\title{
O Jornal Última Hora em Curitiba (1959 e 1964)
}

\author{
Fernando Marcelino Pereira ${ }^{1}$
}

- Enviado em 29/02/2016

- Aprovado em 15/06/2016

O jornal Última Hora foi um marco na história do jornalismo brasileiro. Fundado no Rio de Janeiro (na época Estado da Guanabara) por Samuel Wainer, durante o governo eleito de Getúlio Vargas, pretendia expressar uma posição política de defesa do presidente.

A realização da Ultima Hora começa então com a indagação de Vargas a Wainer: “Porque tu não fazes um jornal?" Como relembra Wainer em seu livro de memórias:

Respondi que aquele era o sonho de um repórter com o meu passado. Ponderei que não seria difícil articular a montagem de uma publicação que defendesse o pensamento de um presidente, como era o seu caso, tinha o perfil de um autêntico líder popular.

- Então, faça - determinou Getúlio.

Perguntei se queria saber como faria.

- Não - cortou. - Troque idéias com a Alzira e faça rápido²

Fundado em 12 de junho de 1951, a Última Hora nasceu como um jornal essencialmente político, mas que viria a usar de diferentes estratégias para atrair e conquistar o público, como uma diagramação e um projeto editorial diferenciados, a exploração da charge e da caricatura, e uma utilização inédita da fotografia, especialmente nos esportes.

\footnotetext{
${ }^{1}$ Graduado em Relações Internacionais pela UniCuritiba, Mestre em Ciência Política e Doutorando em Sociologia pela UFPR. Endereço eletrônico: fernandomarcelinopereira@gmail.com
}

2 WAINER, S. Minha razão de viver: memórias de um repórter. Rio de Janeiro: Record, 1988, p. 127. 
0 primeiro número chegou às bancas com uma carta de Getúlio a Wainer, publicada na primeira página. A mensagem havia sido encomendada por Wainer e, conforme ele descobriria depois, na verdade foi escrita em parte por Lourival Fontes, chefe da Casa Civil. Com o jornal, Vargas pretendia romper o cerco da grande imprensa contra seu governo e estabelecer um novo canal de comunicação, ou propaganda, com as massas. Como afirmaria Wainer mais tarde, o vespertino "nasceu estritamente de uma posição política": "era um jornal de oposição à classe dirigente e a favor de um governo". 0 objetivo era romper com "a formação oligárquica da imprensa brasileira e dar início a um tipo de imprensa popular e independente" e visava "atender a sua posição nacionalista, que era uma posição de elite, e de outro lado atender à sua posição popular, que era de reivindicação. (...) Então na frente era um caderno altamente intelectualizado, altamente politizado, e atrás era o caderno da reivindicação. Coisa nova na imprensa brasileira (...) porque os jornais ou eram elitistas ou eram populares, não eram as duas coisas"3.

O projeto gráfico da Última Hora foi elaborado pelo diagramador paraguaio André Guevara. 0 jornal possuía 16 páginas, a princípio, com oito colunas cada uma, e abusava dos recursos visuais. A partir da Ultima Hora houve uma valorização do cartunismo pelo jornalismo brasileiro com a formação de uma equipe profissional com Augusto Rodrigues, Nassara, Lan, Manuel de Araújo Porto Alegre, Ângelo Agostini, Nair de Teffé, Mendez, Théo, Fritz, Aparício Torelli, Hilde, Jaguar, Otávio, Millôr, Henfil, Ziraldo, Claudius e outros.

Com um projeto editorial inovador, a Última Hora atingiu em seis meses uma tiragem de 50 mil exemplares, e, em um ano, já vendia mais de 100 mil às segundas-feiras. Em 1952 já apresentava uma tiragem de 70 mil exemplares. Segundo os dados do Anuário Brasileiro de Imprensa, em 1954 a Última Hora tinha uma tiragem diária de 92 mil exemplares, contra os 110 mil de 0 Globo e os 95 mil de A Notícia, entre os vespertinos de maior tiragem. No mesmo ano, entre os matutinos de maior circulação estavam 0 Dia, com 90 mil exemplares, e o Correio da Manhã, com 72 mil exemplares.

\footnotetext{
${ }^{3}$ Idem, p. 130.
} 
A Última Hora deu início a um tipo de imprensa popular que não existia no Brasil. Até 1950, a opinião pública brasileira era dominada por meia dúzia de jornais, pertencentes a famílias tradicionais havia mais de meio século. 0 resultado imediato foi uma campanha contra a Última Hora, iniciada por Carlos Lacerda e Assis Chateubriand, que ocupou os jornais, as revistas, o rádio, a televisão e o parlamento. As acusações principais foram de dumping, concorrência desleal e favoritismo oficial.

Em agosto de 1952, o deputado Olavo Bilac Pinto, da UDN, denunciou no Congresso que o Banco do Brasil havia emprestado 160 milhões de cruzeiros à Érica e à Última Hora. Wainer contava com o apoio do PSD e do PTB, mas o jogo político escapou às suas mãos quando o deputado Armando Falcão, da UDN, requereu e obteve do Congresso aprovação para a formação de uma CPI para averiguar os financiamentos do Banco do Brasil às quatro empresas pertencentes a Wainer: Cia Paulista Editora de Jornais SA, Empresa Editora Última Hora SA, Érica Editora de Revistas e Publicações SA e Rádio Clube do Brasil. Os políticos da situação conseguiram ampliar a CPI para abranger toda a imprensa, e as duas investigações correram paralelas.

Em 1953, o jornal passou a ser acusado por Carlos Lacerda, dono do jornal concorrente Tribuna da Imprensa, de receber favorecimento para empréstimos feitos pelo Banco do Brasil. Para averiguar as operações, Samuel Wainer sugeriu a criação de uma CPI para averiguar as transações realizadas entre a empresa e o Banco. A CPI foi instaurada em junho de 1953. Ao encerrar suas investigações em novembro de 1953, a CPI concluiu que as empresas jornalísticas em geral faziam negócios com irregularidades junto ao Banco do Brasil.

0 vespertino criado por Wainer dirigia-se especialmente às classes populares, mas não exclusivamente a elas, com penetração em todas as classes sociais. Logo antes do golpe de 1964 a Última Hora chegou a vender 500 mil exemplares em onze edições em sete estados, demonstrando um lugar destacado no confronto social, visto que fora o único jornal de grande circulação a defender a proposta getulista até o dramático suicídio do presidente e, posteriormente, continuou com o editorial pautado no nacionalismo popular apoiando a candidatura de Juscelino Kubitschek à presidência, a posse de João Goulart em 1961 e seu programa de reformas de base. 0 golpe de 1964 selou o destino da Última Hora, que passou a 
ter jornalistas perseguidos e acumular dificuldades econômicas decorrentes do cerceamento político e acabou sendo vendida por Wainer em 1972.

\section{Última Hora em Curitiba}

O jornal nos anos da década de 1950 passou pelo processo de expansão com as edições estaduais em São Paulo, Pernambuco, Minas Gerais e Rio Grande do Sul. No Paraná, além de Curitiba, o jornal tinha sucursais de Londrina, Paranaguá e Ponta Grossa.

A edição curitibana da Última Hora circulou entre 1959 e 1964. Dirigida primeiro por Carlos Coelho e depois Ary de Carvalho, a redação da Última Hora funcionava em duas lojas do edifício Villanova, na Praça Osório com a Rua Voluntários da Pátria, próximo ao Edifício Asa. Tinha mezanino, escada em caracol e mesas enfileiradas nas quais 15 repórteres usavam máquinas de escrever Remingtons e Olivetti.

A Última Hora agregou os melhores jornalistas contestadores da época, como Walmor Marcellino, Mussa José Assis, Jairo Regis, Luiz Geraldo Mazza, Pery de Oliveira, Milton Cavalcanti, Milton Ivan Heller, Adherbal Fortes de Sá Jr., Aramis Millarch, Sylvio Back, Vinícius Coelho, Maurício Fruet, Mauro Ticcianelli, Mauri Furtado, Francisco Camargo, Cícero Cattani, Alenir Dutra, Carlos Augusto Cavalcanti de Albuquerque, Celina Luz, Clóvis de Souza, Edison Jansen, Enéas Faria, Jalvi Ferreira, Miecisleu Surek, Lascir Costa, Francisco Bettega Neto, Walmor Weiss, Maurício Távora, Tato Munhoz da Rocha, Fábio Campana, Nelson Commel e tantos outros.

A Última Hora foi inovadora no formato, na diagramação, no conteúdo e foi responsável pela formação de toda uma geração de jornalistas. 0 jornal tinha 10 páginas, muito moderno para seu tempo.

Última Hora mantinha um estilo mais dinâmico no seu texto, provocativo, publicava a coluna "Fala Povo", como o nome sugere, aberta a opiniões, fazia a cobertura de assuntos que a imprensa paranaense tentava esquecer, promovia o debate de questões nem sempre agradáveis a determinados setores. Esta coluna foi recordista em leitura, sendo rastreada pela 
prefeitura que se pautava nela para agradar a população. A coluna "Luzes da Cidade" fazia cobertura dos clubes e promovendo a escolha da Garota-Luzes. 0 jornal também era muito influente no meio sindical e popular, com coluna dedicada ao sindicalismo, feita por Peri de Almeida; e outra chamada "Plantão Militar" dedicada aos militares informando promoções, cursos, transferências de oficiais da 5a Região Militar, escrita por Walmor Weiss, que também era sargento. 0 jornal também contava com colunas de São Paulo e do Rio de Janeiro, como Stanislaw Ponte Preta.

Impresso em São Paulo, chegava as bancas de Curitiba em torno das 9h. Tinha um preço mais alto que os jornais locais, mas chegou a ter a maior tiragem no Paraná, com média de 30 mil unidades entre 1962 e 1963, mais que a soma de todos os demais no Paraná. Seu recorde de tiragem numa edição foi de 60 mil exemplares, numa época em que Curitiba não tinha mais do que 400 mil habitantes, o que representa um número extremamente significativo até para os dias de hoje.

De 1961 a 1964, a Última Hora transformou-se num dos principais agitadores da campanha da legalidade pela posse de Jango e seu programa de reformas de base. Entretanto, isso não impediu a Última Hora de articular interesses comerciais e acordos políticos locais, onde era simpático ao governo Ney Braga, apoiou a candidatura de Ivo Arzua Pereira a prefeito de Curitiba e a dobradinha Amaury-Adolpho para o Senado.

As atividades políticas permeavam o ambiente da Última Hora. Diversos de seus jornalistas foram protagonistas da histórica greve de 1963. Em novembro daquele ano, trabalhadores gráficos e jornalistas realizaram uma paralisação conjunta de quatro dias, que impediu a produção e circulação dos jornais Gazeta do Povo, Diário do Paraná e O Estado do Paraná.

Dias antes do golpe de 1964, a sede da Última Hora foi apedrejada por estudantes do colégio Santa Maria, liderado por membros do movimento Família e Propriedade. Com o golpe em abril de 1964, seus jornalistas foram perseguidos e a Última Hora que teve que fechar as portas em 13 de maio de 1964. 
Cerca de 20 jornalistas foram indiciados em Inquérito Policial Militar por envolvimento em "atividades subversivas, comunistas e contrarrevolucionárias". Se condenados, poderiam pegar pena de 20 a 44 anos de prisão. O IPM durou quatro anos e todos os réus foram absolvidos por decisão do Tribunal Superior Militar, contando com a defesa liderada por René Dotti. Entretanto, muitos inclusive jornalistas ficaram impedidos de exercer a profissão e vários foram presos arbitrariamente durante a ditadura, como Walmor Marcellino, Edésio Passos, Luiz Manfredine, Walmor Weiss e Aloísio Palmar.

A Última Hora de Curitiba formou uma equipe editorial que entrou para a história da mídia impressa paranaense como um autêntico veículo de comunicação, participativo dos períodos representativos da política brasileira e integrada com ações da comunicação política nacional. Talvez seja sido o instrumento de comunicação alternativa mais importante daqueles cerca de 150 periódicos que, entre 1964 e 1980, nasceram e morreram no Brasil. 